\title{
A picture is worth a thousand words
}

\author{
K Michael Cummings
}

We have all heard the expression "a picture is worth a thousand words". While there is a lot of truth to this expression, often times we ignore this advice when communicating to people about the health risks of smoking. More times than not, when asked to explain the deadly effects of smoking, we do so by presenting an avalanche of statistics which are easily misunderstood and discounted.

The cover of this issue of Tobacco Control uses the portraits of famous people who have died of smoking-caused disease to communicate the deadly health consequences of smoking. The following page provides a brief biosketch on each of the persons portrayed in the portrait and allows readers to test their knowledge about celebrities who have died from smoking.

The original portrait was done by Albert Ortiz and took more than a year to produce. Mr Ortiz got the idea for the painting after having read an article in a newspaper about Ulysses S Grant, 18th President of the United States, who died of throat cancer from smoking cigars. Mr Ortiz began to investigate the biographies of other famous personalities such as John Wayne, Humphrey Bogart, and Steve McQueen, and he was shocked to learn that all had died of cancer from smoking tobacco. He found it ironic that many of these famous personalities had indeed advertised cigarettes, yet died from use of the product. He felt that had these persons known of the dangers of smoking, many would have never even looked at cigarettes or posed for cigarette advertisements. The more he researched, the more and more upset he became about cigarette smoking.

Mr Ortiz thought that if he could show a picture of these dead celebrities together with a very large blow-up of the Surgeon General's warning that would stretch from edge to edge of his painting, perhaps it would impress people to stop smoking and therefore save their lives. Portraits were painted in black and white so as to add a bit of somberness to the painting.
At the bottom of the $40 \times 48$ inch (102 x $122 \mathrm{~cm}$ ) canvas, he painted five cigarette ads for the most popular brands, choosing the ads he considered most obnoxious.

Mr Ortiz has been kind enought to share his portrait and the information he has collected on each of the celebrities to help health advocates communicate to people about the harmful effects of smoking. Roswell Park Cancer Institute has taken Mr Ortiz's portrait and made it into a handout which has been widely distributed at county fairs, schools, and other public venues. It is one of our most popular handouts.

I guess the lesson from all this is that we should not forget the faces of those who have been victimised by their addiction to tobacco products. Mr Ortiz's portrait of famous people who have died from smoking is a stark reminder of the deadly effects of tobacco use.

\section{Note to readers}

We hereby solicit your ideas and contributions for future covers of Tobacco Control. Like previous covers, we would like future covers to be colourful and creative - with a tobacco control theme. Original artwork, anti-tobacco posters, photographs, and cartoons may all be considered. Material with an international flavour would be particularly desirable. A cover essay will generally appear in each issue to provide appropriate background information and commentary on the cover.

Please send ideas and submissions (originals or high-quality, camera-ready photographs) to the editor at the address on the inside front cover. - ED 


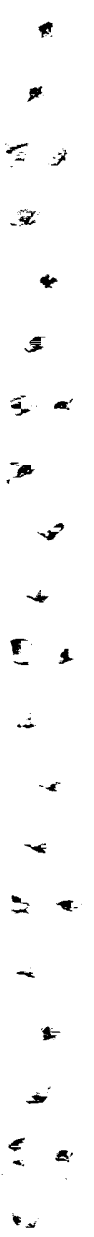

$\leftarrow$

$-$

$\times$

$=$

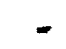

$-$

$=5$

$-$

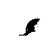

$\leftarrow$

$=\infty$

$-$

5

$-=$

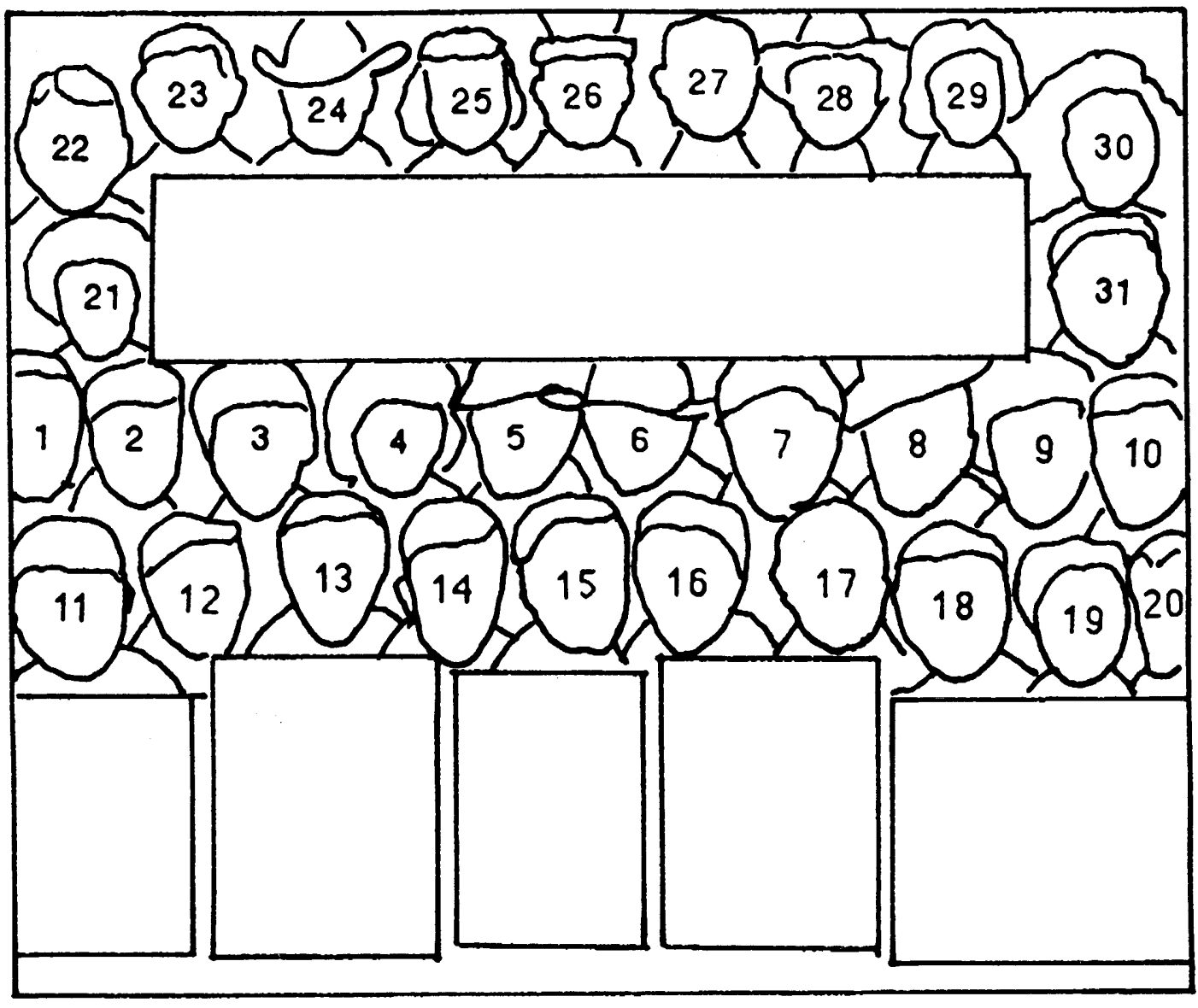

Cover figure: All died from smoking; 23 lung cancer, 1 mouth cancer, 6 emphysema, 1 pancreatic cancer, 4 throat cancer, 2 heart disease.

1 Harry Reasoner News correspondent and co-anchorman on "60 minutes" TV show. Died of heart and lung disease. Chain smoked until his death. Age 68. 2 Chet Huntley News correspondent and co-anchorman of the "Huntley-Brinkley report" on TV. Died of lung cancer caused by smoking. Age 62. 3 Steve McQueen Movie actor. Died of lung cancer. Removal of polyps from his throat and later removal of his right lung. A heavy smoker. Age 50. 4 Michael Landon Movie actor. Died of pancreatic cancer caused by years of heavy smoking, as much as four packs a day. Age 54. 5 Humphrey Bogart Movie actor. Removal of lymph glands caused by smoking. Died of throat cancer. Age 57. 6 John Wayne Movie actor. Died of lung cancer. Left lung removed from smoking up to 5 packs a day. Age 72. 7 Leonard Bernstein Musician and conductor. Chain smoker. Died of lung cancer and emphysema. Age 72. 8 Buster Keaton Movie actor and comedian. Smoked 4 packs a day. Died of emphysema and lung cancer. Age 70.9 Lillian Hellman Author and screen movie writer. Chain smoked. Died from emphysema. Age 79. 10 Arthur Godfrey Television and radio personality. Died of emphysema from years of heavy smoking. Age 80. 11 Rod Serling Movie script writer and narrator of the "Twilight Zone" on TV. Died from a heart attack caused by smoking 4 packs a day. Age 51. 12 Dick York Actor on TV series "Bewitched." Smoked 2 packs a day. Died of emphysema. Age 63. 13 Sammy Davis Jr Entertainer (singer, dancer, actor). Chain smoker. Died of throat cancer. Age 65. 14 Edward R Murrow News correspondent and TV interviewer of famous personalities. Removal of left lung as a result of chain smoking. Died of lung cancer. Age $57.15 \mathrm{Ulysses} \mathbf{S}$ Grant Eighteenth President of the United States. Died of throat cancer caused by cigar smoking. Age 63. Nat King Cole Singer and musician. Removal of left lung. Died of lung cancer. Age 45. 17 Yul Brynner Movie and stage actor. Portrayed the king in "The King and I." Died of lung cancer. Age 65. 18 Desi Arnaz Actor and musician. Producer of "I Love Lucy" TV comedy show. Died of lung cancer. Age 69. 19 Rose Cipollone She and her husband sued the cigarette manufacturer for not alerting her to the dangers of cigarette smoking. She died of lung cancer caused by smoking 2 packs a day. Age 58. 20 Ed Sullivan Newspaper columnist and host of his own $T V$ variety show. Died of lung cancer caused by heavy smoking. Age 72. 21 Nancy Walker Actress and comedian. Died of lung cancer caused by heavy smoking. Age 69. 22 Everett Dirksen United States Senator. Died of lung cancer caused by heavy smoking. Age 75. 23 Neville Brand Movie actor. Portrayed gangsters such as Al Capone. Died of emphysema from smoking. Age 71.24 Wayne McLaren Actor and model for the "Marlboro Man." $A$ heavy smoker himself, did not know the cigarettes he was selling caused disease until he was diagnosed with lung cancer. (His last month of life was spent on a ventilator.) Died of lung cancer. Age 49. 25 Betty Grable Movie actress and entertainer. Died of lung cancer caused by heavy smoking. Age 57. 26 King George VI of England Died of lung cancer shortly after removal of his left lung. A very heavy smoker. Age 57. 27 William Gargan Movie actor. Larynx was removed. Died of throat cancer, caused by heavy smoking. Age 74. 28 James Brown Movie actor. Starred in the "Adventures of Rin-Tin-Tin." Died of lung cancer. Age 72.29 Lee Remick Movie actress. Died of kidney and lung cancer from smoking. Age 56. 30 Tallulah Bankhead Movie actress. Chain smoker. Died of emphysema, caused by heavy smoking. Age 65. 31 Walt Disney Cartoonist and maker of films "Fantasia", "Snow White", "Mickey Mouse", etc. Died of lung cancer. Age 65. Not illustrated: R J Reynolds, Sr. Founder of the $R \mathcal{F}$ Reynolds Tobacco Company. Chewed tobacco and died of mouth cancer. $\mathbf{R} \mathbf{J}$ Reynolds, Jr. Son of founder. Died of emphysema from heavy smoking. Alan J Lerner Author of many Broadway plays including "My Fair Lady". Died of lung cancer caused by heavy smoking. Age 68. William Talman Actor on Perry Mason TV show. Lung cancer. Age 54. Will Thornbury Camel cigarette model. Lung cancer. Age 56. Dick Haynes Movie actor and singer. Lung cancer. Age 61.

Cover : Oil painting on canvas $-40 \times 48$ in. By Albert Ortiz, 3337 Night Hawk Way, Phoenix, Arizona 85044, $U S A$. 